\title{
Spatial Heterogeneity Analysis and Source Identification of Heavy Metals in Soil: A Case Study of Chongqing, Southwest China
}

\section{Wende Chen}

Chengdu University of Technology

Yankun Cai ( $\nabla$ caiyankun621@163.com )

Chengdu University of Technology

Kun Zhu

Chengdu University of Technology

Jun Wei

Chengdu University of Technology

Yutian Lu

Chengdu University of Technology

\section{Research Article}

Keywords: Heavy metals in soil, spatial heterogeneity, classification regression analysis, spatial analysis of hot spots

Posted Date: February 23rd, 2022

DOI: https://doi.org/10.21203/rs.3.rs-1342572/v1

License: (9) (1) This work is licensed under a Creative Commons Attribution 4.0 International License. Read Full License 


\section{Spatial Heterogeneity Analysis and Source Identification of Heavy}

\section{Metals in Soil: A Case Study of Chongqing, Southwest China}

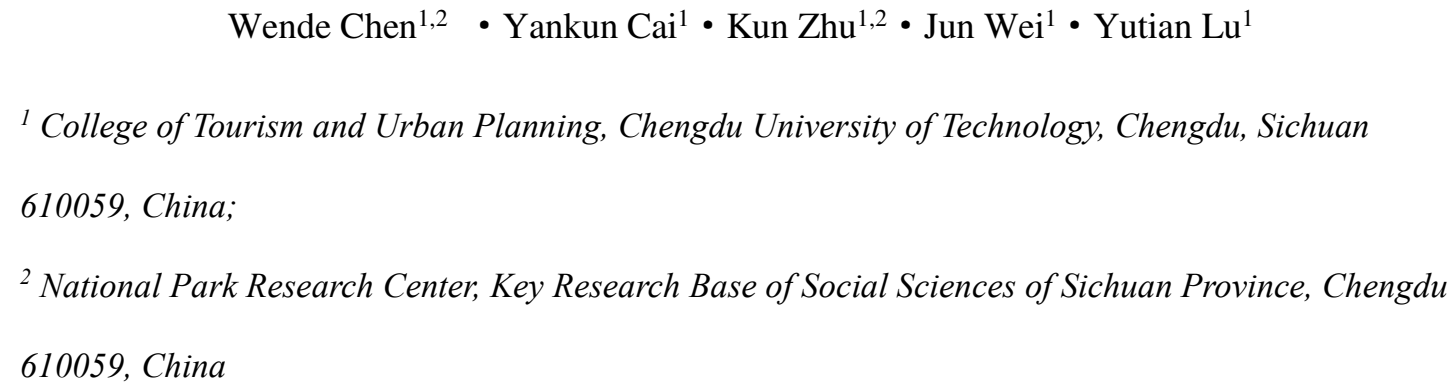

* Corresponding author. Yankun Cai, Master, Chengdu University of Technology, College of Tourism and Urban and Rural Planning.

E-mail addresses: caiyankun621@163.com. 


\title{
Spatial Heterogeneity Analysis and Source Identification of Heavy
}

\section{Metals in Soil: A Case Study of Chongqing, Southwest China}

\begin{abstract}
:
Background: Heavy metal pollution in urban soil is an important indicator of environmental pollution. Selecting the best interpolation method can accurately reflect the distribution characteristics and pollution characteristics of heavy metals in soil. Source analysis and identification of heavy metals in soil can reveal the important content of heavy metal pollution in soil, which is conducive to the implementation of effective management and protection strategies.
\end{abstract}

Materials and methods: In this study, the grid sampling at $40 \mathrm{~cm}$ depth was conducted in the whole study area using the principle of uniform sampling, and the characteristics of $\mathrm{As}, \mathrm{Cu}$ and $\mathrm{Mn}$ in the soil of the main urban area of Chongqing in southwestern China were investigated. The interpolation accuracy and results of ordinary Kriging method (OK), inverse distance weighting method ( IDW ), local polynomial method ( LPI) and radial basis function method ( RBF ) for three elements were analyzed and compared, and the main sources of three heavy metals were studied.

Results: The results showed that $\operatorname{As}\left(5.802 \mathrm{mg} \cdot \mathrm{kg}^{-1}\right), \mathrm{Cu}\left(23.992 \mathrm{mg} \cdot \mathrm{kg}^{-1}\right)$ and $\operatorname{Mn}(573.316$ $\mathrm{mg} \cdot \mathrm{kg}^{-1}$ ) in the soil of the study area were all moderate variations. The prediction smoothing effect of LPI and OK methods on the three metals is strong, which cannot reflect the local point source pollution information. The interpolation results of IDW method and RBF method largely retain the maximum and minimum information of element content. The results of classification and regression analysis confirmed the main sources of heavy metals: population density mainly affected $\mathrm{Cu}(0.539)$, slope mainly affected $\mathrm{Mn}(0.206)$, and water quality mainly affected As (0.453).

Conclusions: The results of this study provide a reference for the formulation of scientific decisions and strategies. Effective soil heavy metal pollution control and management strategies should be developed to ensure the quality of urban soil environment.

Key words: Heavy metals in soil; spatial heterogeneity; classification regression analysis; spatial analysis of hot spots

\section{Introduction}

Due to the changes of natural environment, such as soil-forming process and spatial continuity of climate zone, the characteristics of soil are interrelated and interrelated in space, not uniform and independent(Voronin,1996) with the characteristics of irreversibility, long-term, concealment and hysteresis(Li \& Wu,1991). Soil in the city is an important part of urban environmental factors, and its environmental quality is directly related to human health and safety, which is of great 
significance to the sustainable development of the city. Heavy metals are widely present in various forms in various media of urban environment ( such as atmospheric dry and wet deposition, dust and soil, etc. ). Urban soil is the main gathering place of urban pollutants. The heavy metals carried by these pollutants also enter the urban soil in large quantities, resulting in heavy metal pollution in urban soil, resulting in the degradation or even loss of original function of urban soil(Chen et al.,2016). Heavy metal pollution in urban soil is an important indicator of environmental pollution. Heavy metal pollution in urban soil has become the focus of urban environmental pollution research.

Geostatistics is a mathematical geological method based on regionalized variables and spatial correlation and variation functions. After years of development, geostatistics has developed into a mature tool to study spatial variability, which can maximize the preservation of spatial variability information. Geostatistics has reached a mature stage in the application of mineral geology, and has also been widely used in hydrology, soil science and other fields(Chen et al.,2005). Optimization of spatial interpolation method is the key to accurately predict spatial distribution characteristics and pollution risk of heavy metal elements in regional soil (Ma et al. , 2018). The selection of interpolation model determines the effect of soil heavy metal pollution evaluation. The spatial interpolation methods that are widely used in soil heavy metal pollution evaluation include inverse distance weighting method, Kriging interpolation method, spline function method, multiple regression method, radial basis function method, etc(McGrath et al.,2004; Zhao et al.,2020).

With the development and progress of industry, people gradually realize the threat and impact of heavy metals on the human body. Scholars began to study heavy metals in the 1980s and 1990s. DeRosa(DeRosa et al.,1991)evaluated the impact of environmental toxic lead on children 's physical or mental development. Before 2000, the research mainly focused on the spatial distribution and pollution assessment of heavy metal pollution. With the development of geostatistics, Kriging and inverse distance weighted interpolation methods have been widely used in spatial distribution research. From 2000 to 2010, the research focused on pollution index, spatial variation, biological stimulation and biological monitoring of heavy metal risk assessment. After 2010, the monitoring of heavy metal pollution sources has become a hot topic. At present, the source analysis models widely used in the soil field mainly include absolute factor analysis / multiple linear regression (APCS / MLR) model, positive definite matrix factorization (PMF) model, UNMIX model, isotope ratio method, etc. Due to 
the differences of soil parent material, climatic conditions and human disturbance, the sources of heavy metals are quite different. It is necessary to detect specific sources of heavy metals in sites. For example, Liu(Liu et al.,2021) found that heavy metals $\mathrm{Hg}$ in agricultural soil in southern Shandong Peninsula of China came from coal combustion, $\mathrm{Cd}$ came from agricultural practice, $\mathrm{Cu}, \mathrm{Pb}$ and $\mathrm{Zn}$ came from agricultural practice and industrial activities, as well as industrial activities. Aguilera(Aguilera et al.,2021) expounded that the main sources of heavy metals $\mathrm{Pb}, \mathrm{Zn}, \mathrm{Cu}$ and $\mathrm{Cr}$ in street dust of Mexico City were human activities, which might be caused by vehicle traffic. Ivankovic(Ivankovic et al.,2010) believed that the heavy metal Ni in the urban soil of Belgrade in Serbia came from peridotites and serpentinites, and $\mathrm{Pb}$ came from traffic activities.

Therefore, the purpose of this study is:(1) To describe the characteristics of $\mathrm{As}, \mathrm{Cu}$, Mn content in soil of Chongqing city; (2) Four interpolation methods, ordinary Kriging (OK), inverse distance weighting (IDW), local polynomial interpolation (LPI) and radial basis function (RBF), were used to visualize the distribution of three heavy metal pollutions and reveal the spatial distribution law of soil heavy metal content;(3) The relationship between heavy metals and environmental factors was analyzed by CATREG;(4) The spatial variation of heavy metal content in soil was analyzed by ArcGIS hotspot analysis.

\section{Materials and methods}

\subsection{Study area}

Chongqing is located in southwestern China and the upper reaches of the Yangtze River, spanning $105^{\circ} 11^{\prime}-110^{\circ} 11^{\prime} \mathrm{E}$ and $28^{\circ} 10^{\prime}-32^{\circ} 13^{\prime} \mathrm{N}$, and is located in the transition zone between the Qinghai-Tibet Plateau and the middle and lower reaches of the Yangtze River. Chongqing ' $s$ terrain gradually reduced from north-south to the Yangtze River valley. The northwest and central parts of Chongqing are mainly hills and low mountains. The southeast part of Chongqing is located in the two mountains of Daba Mountain and Wuling Mountain.

The main urban areas of Chongqing include the six districts of Yuzhong, Jiangbei, Dadukou, Shapingba, Nanan and Jiulongpo in the core urban area and the three districts of Banan, Yubei and Beibei in the peripheral metropolitan area. The study area belongs to subtropical monsoon humid climate with warm winter and hot summer. The annual average temperature is $16 \sim 18{ }^{\circ} \mathrm{C}$. The average temperature in January is $5 \sim 7.9^{\circ} \mathrm{C}$. The average temperature in July is $28 \sim 34.4^{\circ} \mathrm{C}(\mathrm{WU}$ et al.,2011). The Yangtze River runs across the central part of the study area, and there is a confluence of Jialing River 
in the north. There are many rivers with long history and abundant water. Due to the complex lithology of the parent rock, the soil types in the study area are rich and diverse, which can be divided into 8 soil types including paddy soil, neo-accumulative soil, yellow soil, yellow brown soil, purple soil, limestone soil, red soil, mountain meadow soil and 16 subgroups.

\subsection{Soil sampling and data collection}

Soil samples were collected in the main urban area of Chongqing City in China. According to the characteristics of the study area, grid sampling was carried out in the whole study area with the assistance of GPS and the principle of uniform distribution sampling. The sampling depth is $40 \mathrm{~cm}$, and the sampling density is $4 \mathrm{~km}$. Three multipoint collection combinations are located within $100 \mathrm{~m}$ around the sampling center. Four sampling points are determined by taking the sampling point of GPS positioning as the center and radiating $40 \mathrm{~m}$ around it (Fig. 1). 342 samples were collected from 9 districts of Chongqing. The samples collected in the field were sealed in plastic bottles and sent to the laboratory of Anhui Rock and Mineral Testing Center with national firstlevel qualification for testing. The detection was carried out according to the geological survey technical standard of China Geological Survey ' Ecological Geochemical Evaluation Sample Analysis Technical Requirements (Trial) ' (DD2005-03 ). Different determination methods were used for the samples, and the detection limits of $\mathrm{As}, \mathrm{Cu}$ and $\mathrm{Mn}$ in the samples were calculated. The detection limits reached $\mathrm{mg} \cdot \mathrm{kg}-1$, which could meet the rapid analysis requirements of Class II soil in the national soil environmental quality standards. Air quality, population density and water quality are derived from the statistical yearbook (2000-2010). In order to describe the impact of industrial activities on heavy metals more accurately, industrial GDP is used to characterize the intensity of industrial activities. Population distribution (2000a) is the result of the fifth census in China. Land use data (1:100000), elevation data (DEM) ( 1 : 250000), slope and traffic data $(1: 250000)$ are all from the resource and environmental data cloud platform ( http://www.resdc.cn/default.aspx) ). Soil type (1:1000000) from China Soil Database (http://vdb3.soil.csdb.cn/), soil parent material (1:500000) from China Geological Map. 


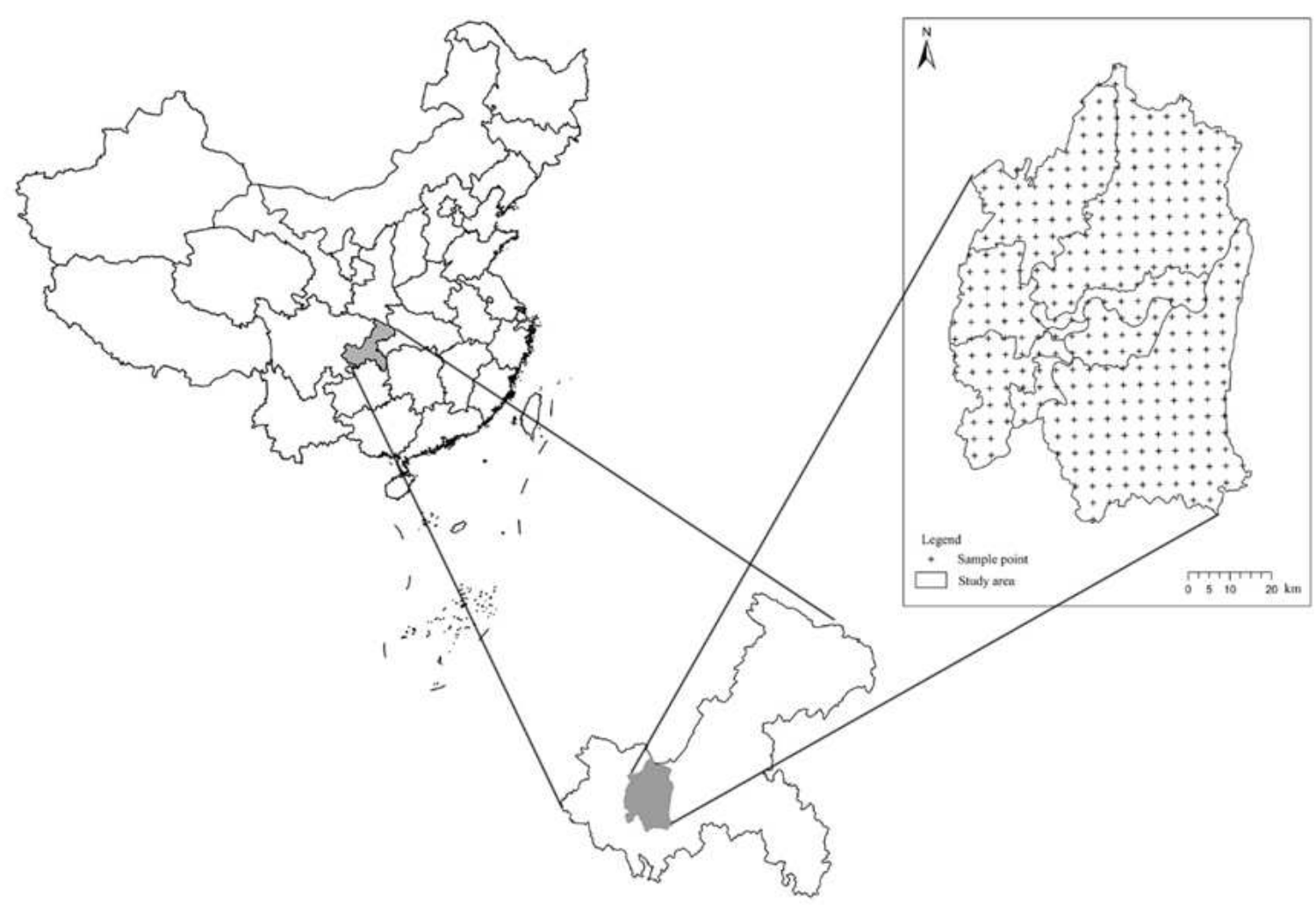

Fig 1 Distribution of soil sampling points and urban areas in Chongqing

Standard statistical analysis includes the maximum, average, standard deviation, coefficient of variation, etc., to illustrate the soil $\mathrm{As}, \mathrm{Cu}$ and $\mathrm{Mn}$ reserves and trends. In order to meet the normality assumption of geological statistical analysis, GS +10.0 is used for logarithmic transformation of original data, and inverse transformation is carried out through weighted average. In this study, four interpolation methods including ordinary Kriging (OK), inverse distance weighting (IDW), local polynomial (LPI) and radial basis function (RBF) were compared, and the distribution maps of As, $\mathrm{Cu}$ and $\mathrm{Mn}$ reserves in soil were generated in ArcGIS 10.2.

\subsection{Soil quality assurance $(Q A)$ and quality control $(Q C)$}

Strict quality control is ensured during the experiment. All samples are analyzed in triplicate. In this study, soil elements were determined by inductively coupled plasma optical emission spectrometry (ICP-AES), X-ray fluorescence spectrometry (XRF) and atomic fluorescence spectrometry (AFS). The recoveries of $\mathrm{Cu}, \mathrm{As}, \mathrm{Mn}$ were 91-104\%, $97-105 \%$ and $90-93 \%$, indicating that the method used has high accuracy and can meet the requirements of detection and analysis. The relative standard deviation of all 
elements is less than $6 \%$, which proves that the method has high repetition rate and good precision. The detection limits of $\mathrm{Cu}, \mathrm{As}, \mathrm{Mn}$ were $1,0.2$ and $5 \mathrm{mg} / \mathrm{kg}$, respectively, and the relative deviations were all less than $10 \%$.

\subsection{Theory and method of spatial variation based on geostatistics}

\subsubsection{Analysis of spatial structure characteristics}

Geostatistics is a mathematical method based on the theory of regionalized variables and the semi-variance function as the basic tool. It is based on the concepts of regionalization variable, random function, implication hypothesis and stationary hypothesis. Semi-variogram, also known as semi-variogram, is a key function for studying soil variability in geostatistics. Usually, the grid sampling method is used to estimate the semivariance function of soil properties, which has conditional negative qualitative. The calculation formula is(LIUQing et al.,2011):

$$
\gamma(h)=\frac{1}{2 N(h)} \sum_{i=1}^{N(h)}\left|Z\left(X_{i}\right)-Z\left(X_{i+h}\right)\right|^{2}
$$

$N(h)$ :Number of pairs of all observation points with h spacing $(\mathrm{N}(\mathrm{h})=\mathrm{n}-1$ if there are $\mathrm{n}$ sampling points); $\gamma(h)$ : Semivariance, usually a semivariance function graph in a characteristic direction for $h$ with $\gamma(\mathrm{h})$.

Semi-variance function has three extremely important parameters, namely, block gold value (Nugget), range (Range) and base value (Sill). They are quantitative indicators of spatial variation and correlation degree of regionalized variables at a certain scale. Nugget $\left(\mathrm{C}_{0}\right)$ represents a variation caused by non-sampling point spacing, which is a random variation and reflects the spatial variation caused by random factors such as socio-economic factors(Wang et al.,2002). Range (a) reflects the spatial variability of soil properties, and analyzes the mobility of variables, i.e. spatial dependence, which is spatially independent outside the range and is correlated within the range. The base value $\left(\mathrm{C}_{0}+\mathrm{C}\right)$, also known as the top value, refers to the maximum value of semivariance in different sampling intervals, reflecting the spatial variation caused by natural factors ( such as soil parent material, topography, etc. ) and socioeconomic factors ( such as fertilization, planting system, etc. ), which is composed of random variation and structural variation(Wang et al.,2019). The purpose of analyzing the spatial structure characteristics of variables is to use the determined best fitting model of semi-variance function and its Nugget $\left(\mathrm{C}_{0}\right)$, Sill $\left(\mathrm{C}+\mathrm{C}_{0}\right)$, nugget effect $\left(\mathrm{C}_{0} /\right.$ $\mathrm{C}+\mathrm{C}_{0}$ ) and range (a), and combine the spatial correlation distance to evaluate the spatial correlation of each attribute, and analyze its variation law, variation degree and causes of variation(LIUQing et al.,2011). 


\subsubsection{Ordinary kriging}

Ordinary Kriging $(\mathrm{OK})$ is based on the theory of regionalized variables, and the main tool is variation function. The advantage of this method is to consider the random distribution of sample points in spatial structure. The accuracy of the estimated value depends on the selection of the weight coefficient, and the optimal weight coefficient depends on the selection of the mutation function model(Xie et al.,2018). The variation function is used to calculate the integrity of spatial continuity in one or more directions(Schöning et al.,2006). In order to more accurately reflect the spatial heterogeneity of soil heavy metal elements, their theoretical models are constructed according to the determination coefficient $\mathrm{R}^{2}$ and residual of semi-variation function. Linear model, spherical model, exponential model and Gaussian model can be selected to construct the semi-variation function of heavy metal content in surface soil. The best model is selected to analyze the spatial structure and provide the input parameters of interpolation(Zhang,2005).

\subsubsection{Inverse Distance Weighting}

Inverse Distance Weighting (IDW) is a simple interpolation method based on Tobler theorem(NIU,2011). Sets that each measurement point is affected locally, which is inversely proportional to the distance. The principle is that the interpolation is carried out by the weighted average of the measured values of each point near the measured point. According to the spatial autocorrelation principle(Kebaili Bargaoui \& Chebbi,2009), the weight of the point nearest to the predicted position is larger, and the weight is reduced as a function of the distance.

$$
Z=\frac{\sum_{i=1}^{n} \frac{Z_{i}}{D_{i}^{r}}}{\sum_{i=1}^{n} \frac{1}{D_{i}^{r}}}
$$

$\mathrm{Z}$ is the estimated value of the interpolation point, $\mathrm{Z}_{\mathrm{i}}(\mathrm{i}=1 \sim \mathrm{n})$ is the measured sample value, $n$ is the measured sample number used to estimate, $D_{i}$ is the distance between the interpolation point and the $i$ control point, $r$ is the power of the distance, $r$ $=2$.

\subsubsection{Local polynomial interpolation}

This method is suitable for the polynomial with a given order to interpolate all the points in the search neighborhood. The surface formed mainly depends on local variation, which is vulnerable to the influence of the distance between adjacent regions. The case of small range variation in the data set is most suitable for this method.

$$
\mathrm{Z}\left(\mathrm{x}_{0}\right)=\mathrm{f}(\mathrm{x})
$$




$$
R(x)=f(x)-P(x)
$$

It satisfies $\operatorname{Pn}\left(x_{i}\right)=y, i=0,1,2, \ldots, n$

$\mathrm{x}_{\mathrm{i}}$ is the interpolation node, $\mathrm{n}$ is the number of samples, $\mathrm{Z}\left(\mathrm{x}_{0}\right)$ is the predictive value of the first sample, $\mathrm{R}(\mathrm{x})$ is the interpolation term, $\mathrm{f}(\mathrm{x})$ is the kernel function(Dean et al.,2017).

\subsubsection{Radial basis function}

The radial basis function is used to approximate the predicted value of the measured function $\mathrm{F}=\mathrm{F}(\mathrm{x})$. The core of the radial basis function is to construct the approximation function. Compared with other interpolation methods, it is more complex and suitable for interpolation of large amounts of data.

$$
z(x)=\sum_{i=1}^{n} \alpha_{i} \varphi\left(d_{i}\right)+\sum_{j=1}^{m} b_{j} f_{j}(x)
$$

$\varphi\left(d_{i}\right)$ is the radial basis function $d_{i}$ is the distance between the interpolation point $i$ and the sampling point $\mathrm{x}$, and $\mathrm{f}_{\mathrm{j}}(\mathrm{x})$ is the trend function.

\subsubsection{Data verification}

Prediction Accuracy of As, $\mathrm{Cu}$ and Mn by Cross Validation(Gotway et al.,1996; Liu et al.,2013; Rodriguez Martin et al.,2016). The cross-validation method assumes that the content value of each sampling point is unknown, and uses the value of the surrounding sample point to estimate, then calculates the error between the estimated value and the actual measured value, and evaluates the advantages and disadvantages of the interpolation method according to the error statistical results(Robinson \& Metternicht,2006). The commonly used indicators are root mean square error (RMSE), mean error (ME) and inaccuracy (IP), which are used to compare the interpolation accuracy of different methods. These indices are calculated as follows:

$$
\begin{aligned}
& \text { RMSE }=\sqrt{\frac{1}{n} \sum_{i=1}^{n}\left(P_{i}-M_{i}\right)^{2}} \\
& M E=\frac{1}{n} \sum_{i=1}^{n}\left(P_{i}-M_{i}\right) \\
& I P=R M S E^{2}-M E^{2}
\end{aligned}
$$

$\mathrm{P}_{\mathrm{i}}$ and $\mathrm{M}_{\mathrm{i}}$ represent the predicted value, measured value and measured average value respectively.

\subsection{CATREG}

In order to identify the relative importance of variables affecting heavy metals, CATREG model, as a non-parametric multivariate regression analysis model, can use an optimal scaling program to scale the dependent variables and independent variables, 
and analyze the classified variables and numerical variables. It is usually used to test the influence of multiple prediction factors on the dependent variables(Almeida \& Garrod,2018; Feng et al.,2021). The classification regression (CATREG) selected in this study is analyzed, and the discrete variables pre-variables are selected into the regression. Category quantization is to quantify the class variables by a specific nonlinear transformation, and then iteratively find the optimal equation directly. CATREG Model is a Classical Linear Regression Model with Application and Transformation Variables(Yang et al.,2020).

GATREG is a econometric method used to deal with data sets containing nominal, ordinal and interval variables. In the simple linear regression model, a response variable is predicted from $\mathrm{m}$ prediction variables in $\mathrm{x}$, trying to find a linear combination $\mathrm{Xb}$ with the largest correlation. The ' optimal scaling ' in volved in the feasible nonlinear function analysis between $Z$ and $\sum_{j=1}^{m}\left(b_{j} \varphi_{j}\left(X_{i}\right)\right)$ is expressed as:

$$
\left\|X^{*} b-Z^{*}\right\|^{2} \text { where }\left\|X^{*} b-Z^{*}\right\|=\sqrt{\left(X^{*} b-Z^{*}\right)^{T}\left(X^{*} b-Z^{*}\right)}
$$

The classification variable $h_{j}$ defines the binary indicator matrix $G_{j}$ of n rows and columns $l_{j}$, where $h_{i j}$ defines $g_{i r(j)}$ as follows:

$$
\left\{\begin{array}{l}
g_{i r}(j)=1, h_{i j}=r \\
g_{i r}(j)=0, h_{i j} \neq r
\end{array}\right.
$$

The $\mathrm{r}=1,2 \ldots \ldots l_{j}$ is the running index, indicating the class number in $\mathrm{j}$. If the class quantization can be expressed by $y_{j}$, then the variable of transformation can be written as $G_{j} y_{j}$. For example, the weighted sum of the predictor variables can be expressed as:

$$
\sum_{j=1}^{m} b_{j} G_{j} y_{j}=X^{*} b
$$

This is the same as the standard linear model. Finally, Gatreg is equivalent to a linear regression model, which can be expressed as follows:

$$
Z^{*}=X^{*} b+\varepsilon
$$

In the formula, $X^{*}$ represents the coefficient matrix, $Z^{*}$ is the observed value vector, $\mathrm{b}$ is the normalized coefficient vector, and $\varepsilon$ is the error vector. The qualitative variables are transformed into quantitative variables through the optimal scaling process. Classification variables are quantified to reflect the characteristics of the original category, and the use of nonlinear transformations allows the analysis of variables at various levels to find the best fit model. 


\section{Results and discuss}

\subsection{Descriptive statistical analysis}

Table 1 shows the descriptive statistics of $\mathrm{As}, \mathrm{Cu}$ and $\mathrm{Mn}$ in the study area. The content of As in soil heavy metals in the main urban area of Chongqing was $1.965-$ $21.180 \mathrm{mg} / \mathrm{kg}$, and the difference between the maximum and minimum was 10.8 times. The average content $(5.802 \mathrm{mg} / \mathrm{kg})$ was lower than the background value $(6.62 \mathrm{mg} / \mathrm{kg})$ of soil in Chongqing. Among the three elements, the variation coefficient of As element (55.71\%) was the highest. The content of Mn ranged from $107.900 \mathrm{mg} / \mathrm{kg}$ to 1584.000 $\mathrm{mg} / \mathrm{kg}$. The difference between the maximum value and the minimum value was 14.7 times. The average value $(573.316 \mathrm{mg} / \mathrm{kg})$ was lower than the background value $(615.00 \mathrm{mg} / \mathrm{kg})$ in Chongqing. The coefficient of variation of Mn (32.21\%) was the lowest. The range of $\mathrm{Cu}$ content was $6.208-76.600 \mathrm{mg} / \mathrm{kg}$, and the difference between the maximum and minimum was 12.3 times. The average value $(23.992 \mathrm{mg} / \mathrm{kg})$ was not significantly different from the soil background value $(24.60 \mathrm{mg} / \mathrm{kg})$ in Chongqing, and the coefficient of variation $(32.21 \%)$ was moderate.

Table 1 Descriptive statistical analysis of soil heavy metal content

\begin{tabular}{|c|c|c|c|c|c|c|c|}
\hline \multirow{2}{*}{ Heavy metal } & \multicolumn{5}{|c|}{ Study area $\left(\mathrm{mg} \cdot \mathrm{kg}^{-1}\right)$} & \multirow{2}{*}{$\begin{array}{c}\text { Soil background } \\
\text { value in Chongqing } \\
(\mathrm{mg} / \mathrm{kg})\end{array}$} & \multirow{2}{*}{$\begin{array}{c}\text { Point over- } \\
\text { standard } \\
\text { rate } 1 \%\end{array}$} \\
\hline & Maximum & Minimum & Mean & SD & $\mathrm{CV} / \%$ & & \\
\hline As & 21.180 & 1.965 & 5.802 & 3.2323 & 55.71 & 6.62 & $28.07 \%$ \\
\hline $\mathrm{Cu}$ & 76.600 & 6.208 & 23.992 & 8.572 & 35.73 & 24.60 & $33.63 \%$ \\
\hline $\mathrm{Mn}$ & 1584.000 & 107.900 & 573.316 & 184.685 & 32.21 & 615.00 & $33.92 \%$ \\
\hline
\end{tabular}

$\mathrm{SD}=$ standard deviation; $\mathrm{CV}=$ coefficient of variation;-*

\subsection{A theoretical model of GS+ fitting semi-variance function}

After the analysis and fitting of the variation function, the best variation function model is selected based on the principle of the maximum determination coefficient $\left(\mathrm{R}^{2}\right)$ and the minimum residual error (RSS). Table 2 shows the optimal theoretical model and related parameters selected for semi-variance fitting of three heavy metals. The results show that the semi-variance theoretical models of As and Mn are Gaussian model, and the semi-variance theoretical model of $\mathrm{Cu}$ is Exponential model. Spatial correlation is the result of structural factors and random factors. structural factors such as parent material, soil type, climate and other soil-forming factors ; random factors include farming, management measures, cropping systems, pollution and other human activities(Wang et al.,2020; Zheng et al.,2006).

Table 2 Theoretical Model and Related Parameters of Heavy Metal Content in Soil 


\begin{tabular}{cccccccc}
\hline Element & Theoretical model & $\mathrm{C}_{0}$ & $\mathrm{C}+\mathrm{C}_{0}$ & $\mathrm{C}_{0} /\left(\mathrm{C}+\mathrm{C}_{0}\right)$ & $\mathrm{A}(\mathrm{m})$ & $\mathrm{R}^{2}$ & Residuals \\
\hline $\mathrm{As}$ & Gaussian & 0.023 & 0.230 & 0.100 & 62.4 & 0.988 & $1.200 \mathrm{E}-04$ \\
$\mathrm{Cu}$ & Exponential & 0.066 & 0.150 & 0.437 & 2523.0 & 0.921 & $1.642 \mathrm{E}-04$ \\
$\mathrm{Mn}$ & Gaussian & 0.0001 & 0.088 & 0.001 & 57.2 & 0.921 & $1.572 \mathrm{E}-04$ \\
\hline
\end{tabular}

The parameters showed that the spatial variation of soil heavy metals in Chongqing was as follows: $\left[\mathrm{C}_{0} /\left(\mathrm{C}+\mathrm{C}_{0}\right)\right] \mathrm{Cu}>\mathrm{As}>\mathrm{Mn}$. The ratio of gold value of $\mathrm{Cu}$ element block to base value is $43.7 \%$, which belongs to medium spatial correlation, indicating that its spatial variation is the result of the combined action of random factors and structural factors. It shows that the content of $\mathrm{Cu}$ in surface soil of Chongqing is affected by some random factors ( mainly human input ). H. Khademi(Khademi et al.,2020) once proposed that the concentration of $\mathrm{Cu}$ has a large correlation with particle size. The particle size dependence of metal concentration in street dust and the enrichment degree of $\mathrm{Cu}$ element are higher, indicating that the contribution rate of anthropogenic pollution to $\mathrm{Cu}$ is higher in the economically developed urban areas of Chongqing. However, $\mathrm{Cu}$ in the study area is still controlled by structural factors ( such as climate, parent material, soil type and other natural factors ), and its original spatial pattern has not been destroyed. The block ratio of As and Mn elements is less than $25 \%$, indicating that the system has a strong spatial correlation, and its spatial variation is less affected by random factors. The variable range of $\mathrm{Cu}$ element is large, indicating the control effect of structural factors on $\mathrm{Cu}$ content on the other hand. The ranges of As and $\mathrm{Mn}$ are roughly the same, and they are close to the distance between the sample points, indicating that they are greatly affected by human factors, and the degree of influence by human factors is $\mathrm{Mn}>$ As.

\subsection{Comparison of Four Interpolation Methods}

Check interpolation prediction accuracy by leave-one-out cross validation (Figure 2-4 ). Different scatter patterns indicate that different methods can predict different values at the same point(Liu et al.,2013). The linear model and 1:1 line intersect with $\mathrm{As}, \mathrm{Cu}$ and $\mathrm{Mn}$ contents. On the cross line, the linear model is higher than the contents of $\mathrm{As}, \mathrm{Cu}$ and $\mathrm{Mn}$, and vice versa. This method aims to achieve unbiased estimation of the mean value(Guan et al.,2021; Zhao et al.,2016).

It can be seen from Fig. 2 that the value of IDW method is the largest in the correlation coefficient between the predicted and measured values of As, followed by LPI and RBF, and the value of OK method is the smallest. The correlation coefficient between predicted value and measured value of $\mathrm{Cu}$ element IDW method is the largest, 
followed by LPI and RBF, and OK method is the smallest. The correlation coefficient between the predicted value and the measured value of As element IDW method is the largest, followed by OK and RBF, and LPI method is the smallest. In general, the correlation coefficients between the predicted and measured values of the OK method are between 0.2854 and 0.3186 , the correlation coefficients between the predicted and measured values of the IDW method are between 0.3365 and 0.4384 , the correlation coefficients between the predicted and measured values of the LPI method are between 0.2570 and 0.3949 , and the correlation coefficients between the predicted and measured values of the RBF method are between 0.2325 and 0.3923 . The correlation coefficients of As, $\mathrm{Cu}$ and $\mathrm{Mn}$ in IDW method are higher than those in OK method, LPI method and RBF method.
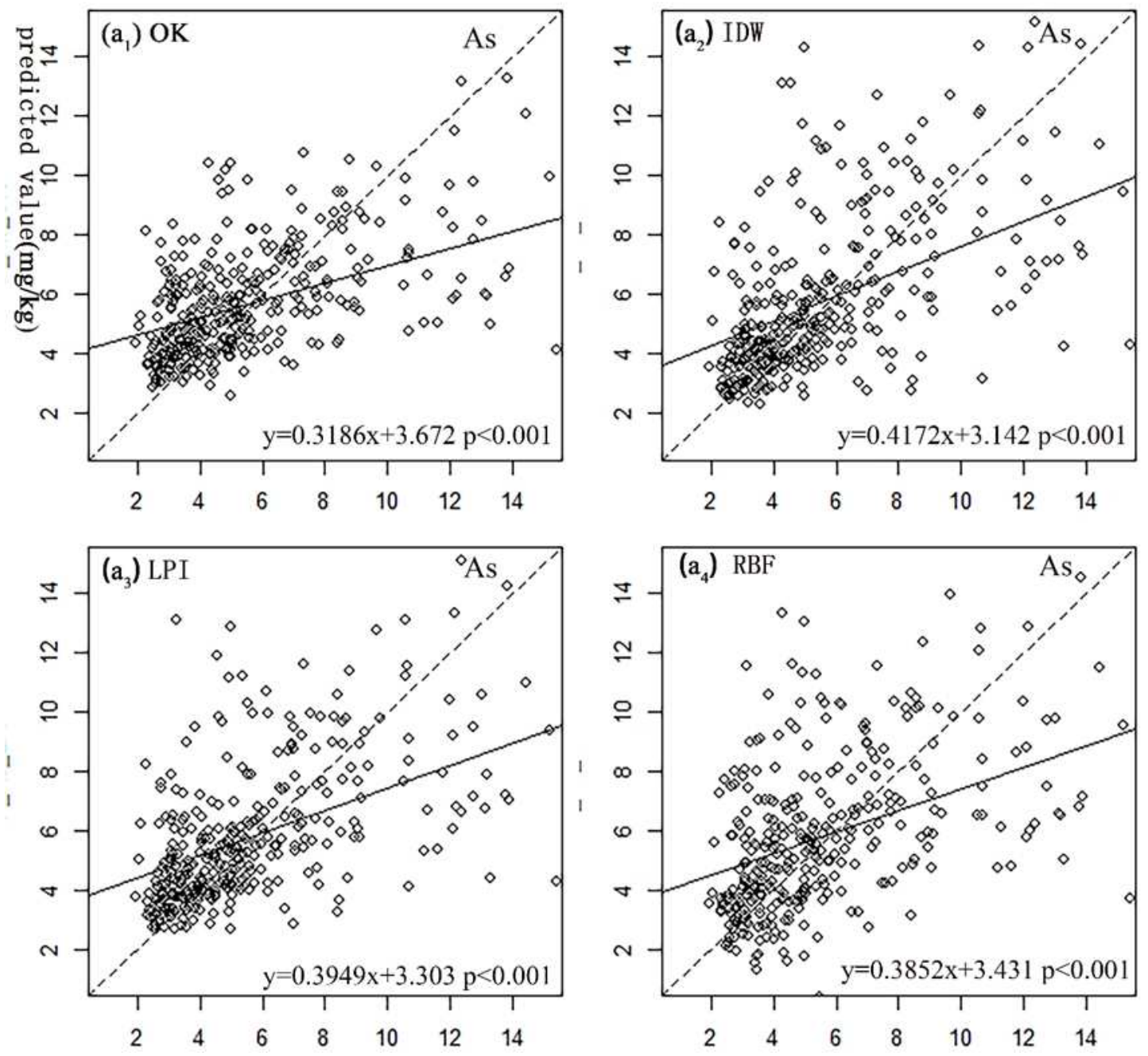

Fig. 2 Cross validation of ordinary Kriging (OK), inverse distance weight (IDW), local polynomial (LPI) and radial basis function (RBF) interpolation methods for As content in soil 

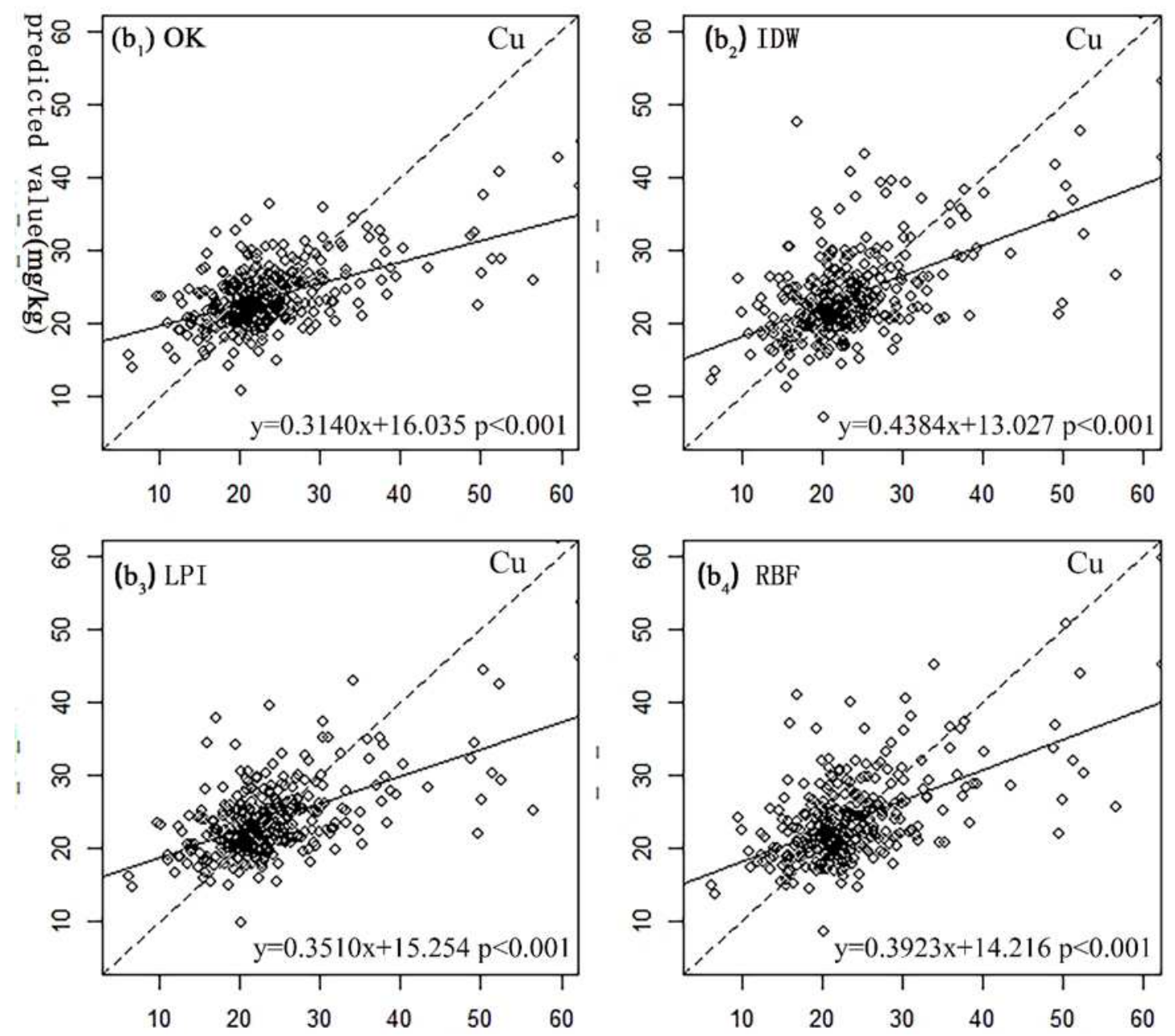

Fig 3 Cross validation of ordinary Kriging ( OK ), inverse distance weight ( IDW ), local polynomial ( LPI ) and radial basis function ( RBF ) interpolation methods for $\mathrm{Cu}$ content in soil 

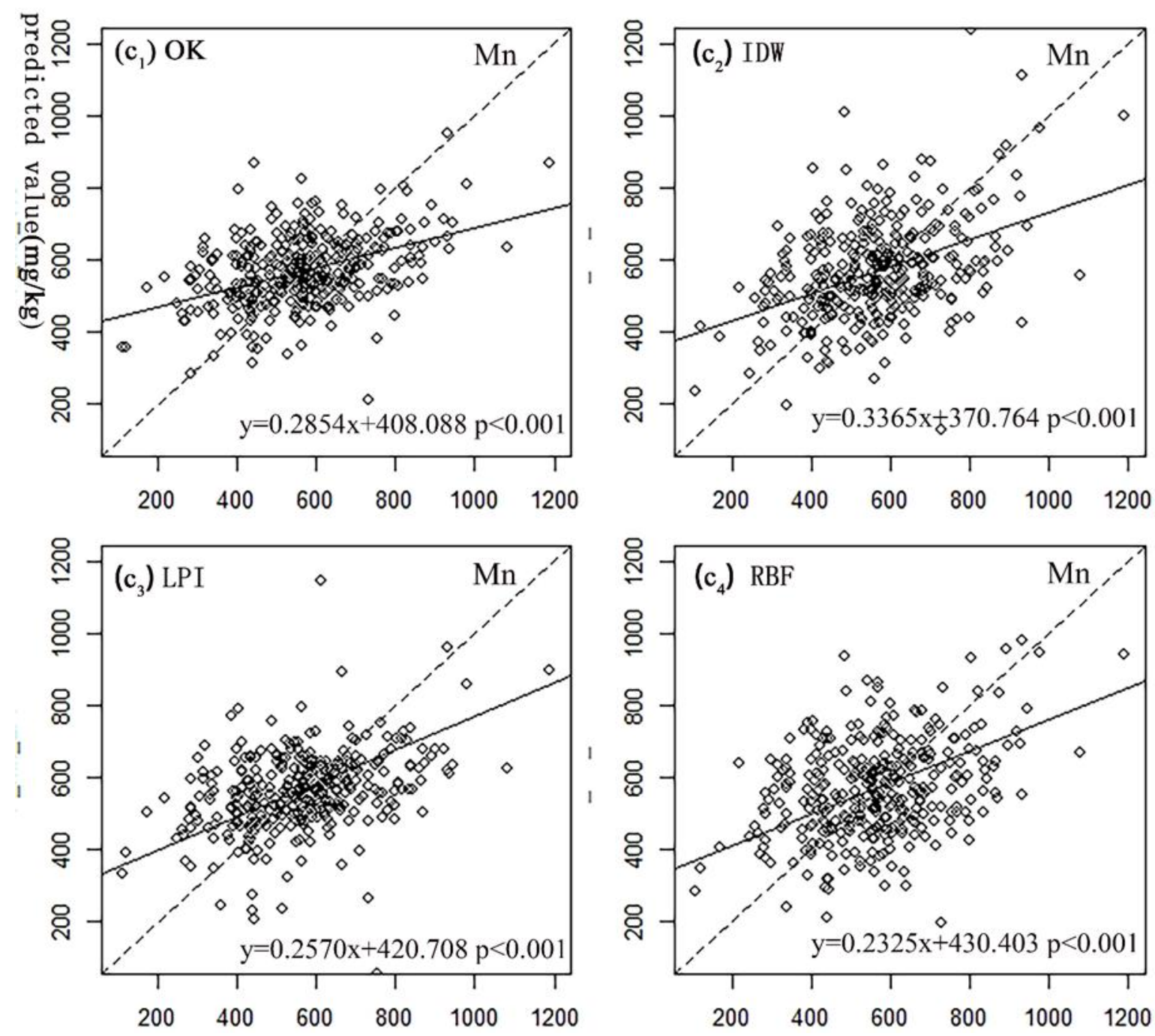

Fig. 4 Cross validation of ordinary Kriging ( OK ), inverse distance weight ( IDW ), local polynomial ( LPI ) and radial basis function ( RBF ) interpolation methods for Mn content in soil

In order to more intuitively compare the accuracy of the four interpolation methods, their mean square error ( RMSE ), mean error ( ME ) and inaccuracy ( IP ) are calculated respectively. The smaller the value of RMSE, the higher the accuracy ; the closer ME to 0 , the smaller interpolation error ; the smaller the IP, the higher the interpolation accuracy.

Table 3 Cross Validation Results of Four Interpolation Methods for As, $\mathrm{Cu}$ and Mn Elements

\begin{tabular}{ccccc}
\hline Element & Interpolation method & RMSE & ME & IP \\
\hline \multirow{3}{*}{ As } & OK & 2.827 & -0.036 & 7.988 \\
& IDW & 3.108 & 0.079 & 9.653 \\
& LPI & 2.978 & 0.015 & 8.868 \\
& RBF & 3.240 & 0.067 & 10.493 \\
& OK & 7.125 & -0.120 & 50.749 \\
\hline
\end{tabular}




\begin{tabular}{ccccc}
\hline & IDW & 7.495 & 0.057 & 56.166 \\
& LPI & 7.012 & -0.026 & 49.170 \\
RBF & 7.119 & 0.024 & 50.688 \\
OK & 162.305 & -0.249 & 26342.950 \\
Mn & IDW & 170.745 & -0.712 & 29153.501 \\
& LPI & 176.729 & 0.078 & 31233.405 \\
& RBF & 171.962 & 1.556 & 29568.343 \\
\hline
\end{tabular}

Table 3 shows the cross validation results of four interpolation methods for $\mathrm{As}, \mathrm{Cu}$ and Mn elements. Comparative analysis shows that for As element, in the four spatial interpolations of OK method, IDW method, LPI method and RBF method, the three elements in RMSE are significantly different, indicating that the predicted values of the three elements are overestimated. For the same element, there is little difference in the degree of overestimation by different methods, among which Mn element is the most overestimated. According to the value of ME, for As element, the values of OK method are closer to 0 , indicating that the predicted values are relatively not biased. The difference between ME and AME of LPI and RBF of $\mathrm{Cu}$ element is small and closer to 1, indicating that the prediction accuracy of LPI and RBF is better. The ME of LPI method of Mn element is closer to 1 than other methods, indicating that the prediction accuracy is good.

\subsection{Prediction of Spatial Distribution of Heavy Metals in Soil}

Cross-validation method is used to evaluate the interpolation error of sample points, which can not reflect the spatial distribution characteristics of interpolation error. According to the interpolation principle of ordinary Kriging (OK), inverse distance weight (IDW), local polynomial (LPI), radial basis function (RBF) and fitting parameters of semivariance function, the spatial variation interpolation was carried out by Geostatistical Analyst module in ArcMap10.2 software, and the spatial distribution trend maps of three heavy metals in soil in the main urban area of Chongqing were drawn. For As, $\mathrm{Cu}$ and $\mathrm{Mn}$ elements, the ordinary Kriging interpolation (OK), inverse distance weighting (IDW), local polynomial (LPI) and radial basis function (RBF) in the statistical module of ArcGIS 10.2 are used for interpolation. The interpolation distribution results are shown in Figures 5, 6 and 7.

From the spatial distribution of As content in surface soil in Chongqing (Fig. 5), it can be seen that the As content of heavy metals in urban surface soil in the whole study area showed a decreasing trend from the periphery to the center, showing a banded 
overall, with north-south directional characteristics. Under four different interpolation methods, As elements show different distribution characteristics. The distribution maps of heavy metals treated by OK, LPI and RBF have a large degree of similarity. However, in the transition region from high concentration to low concentration, the boundary range of pollution area determined by different interpolation methods has great uncertainty. Previous studies have also shown that the enrichment of As elements in the main urban areas of Chongqing is small, but the pollution of tobacco-growing areas in Chongqing is more serious(LI et al.,2006), which reflects that the distribution of As elements has a strong relationship with land use types. 

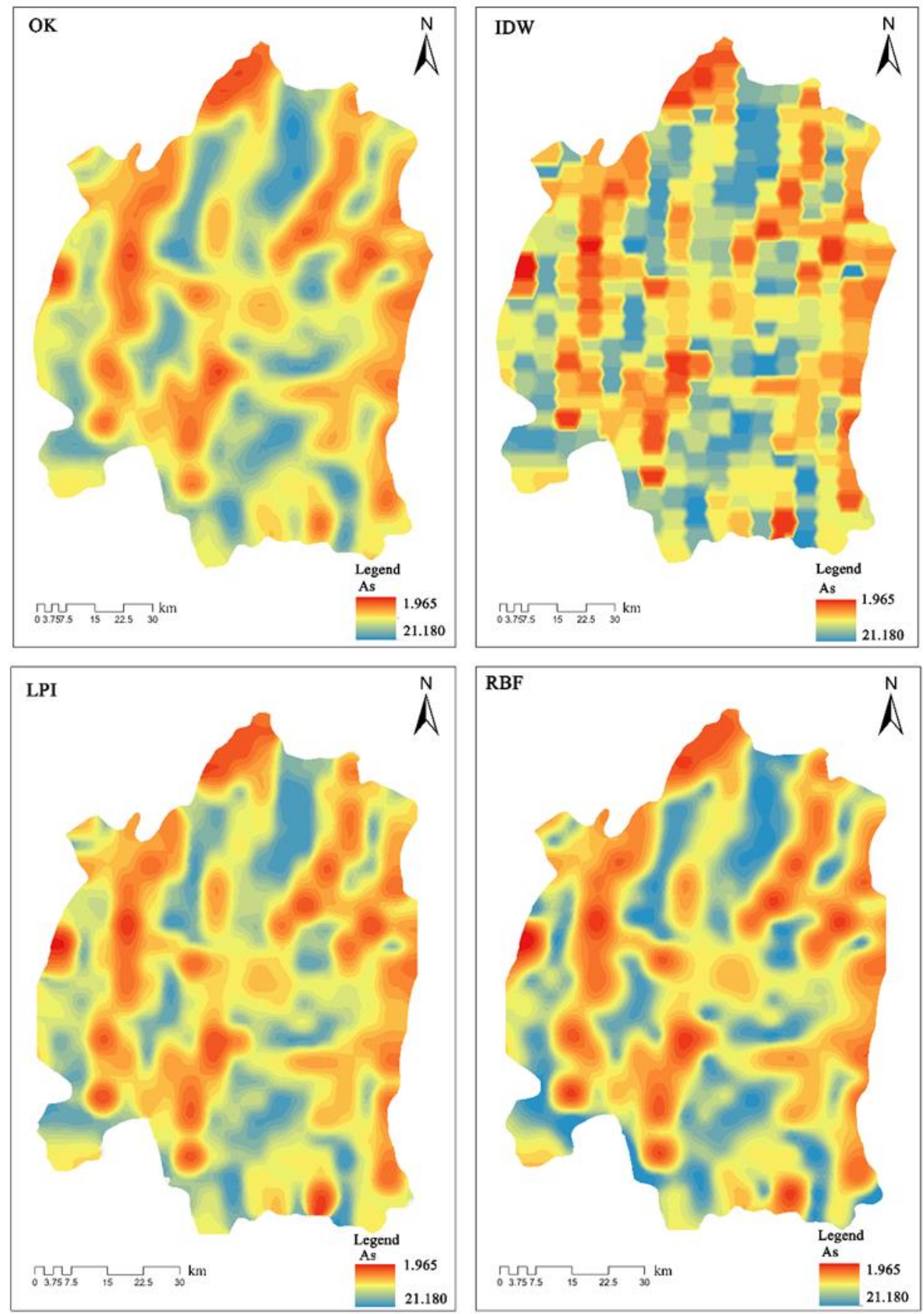

Fig. 5 Spatial distribution of soil heavy metal As by different spatial interpolation methods

Figure 6 is the spatial distribution map of $\mathrm{Cu}$ in the study area under four interpolation methods. It can be seen that the highest value predicted by OK method is distributed in the north and west of the study area, and there are large areas of high value areas in the north and west, and the low value areas are mainly concentrated in the south. The prediction results of IDW method can better reflect the local information of small area. The situation predicted by LPI method is more simple and concentrated, and it reflects the trend and trend of a wide range more smoothly. The RBF method is 
similar to the OK method on the whole, but some local information with small distribution area is missing, which fails to reflect the transition region of high and low values. Through the variation function, it can be obtained that $\mathrm{Cu}$ element is of medium spatial correlation and is greatly affected by the considered factors, which is consistent with previous studies. Guo et al. (Guo et al.,2016) concluded that the soil heavy metal pollution in the main urban area of Chongqing was related to the degree of traffic density, whether there was industrial pollution and the length of urban construction time. The more developed the traffic, the greater the traffic flow, the more serious the accumulation of $\mathrm{Cu}$ element. 

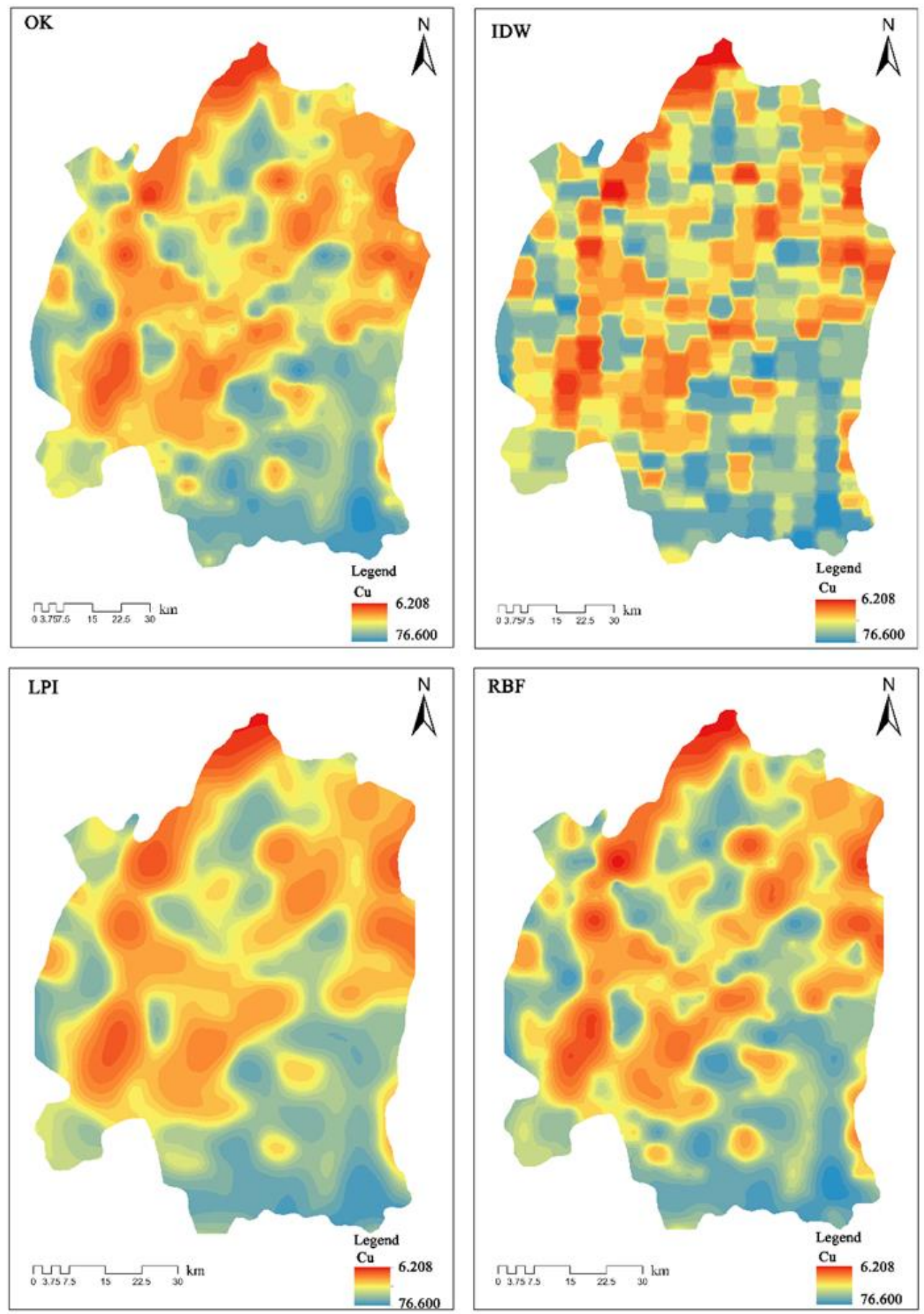

Fig 6 Spatial distribution of heavy metal $\mathrm{Cu}$ in soil by different spatial interpolation methods

Mn content is lower in the southeast of the study area, higher in the north, east and west, the content is gradually increased from southeast to north, east and west, with good continuity. The LPI method reflects the above characteristics but the smoothing effect is too obvious, which cannot accurately reflect the point source pollution and small-scale non-point source pollution. The interpolation results are not as detailed as 
those of the other three methods. The similarity between OK method and LPI method is high, and the change trend of OK method is more obvious. The RBF method fully reflects the pollution situation in a small range of the entire study area, and the performance is more detailed. IDW method can show the characteristics of point source pollution in areas with large concentration, the change trend of content is not obvious, and the pollution degree is more accurate. Mn is less polluted in the main urban area of Chongqing, but the degree of Mn pollution in the mining area is moderate to heavy pollution and the pollution area is more(Yang et al.,2019), indicating that Mn pollution is closely related to artificial mineral exploitation. 

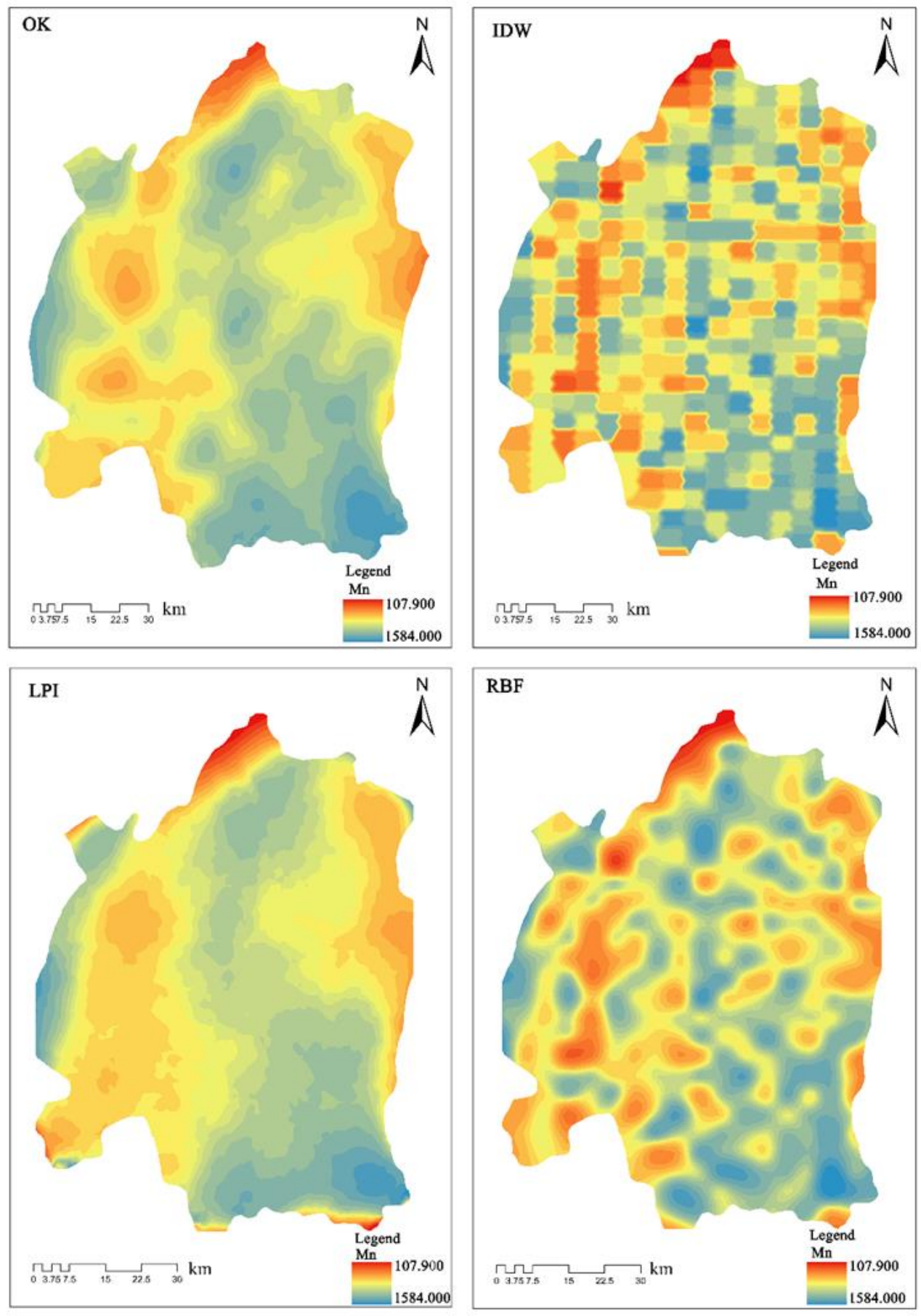

Fig. 7 Spatial distribution of soil heavy metal Mn with different spatial interpolation methods

\subsection{Selection of analytical methods}

Under the premise of using the optimal parameters and fitting model for each interpolation method, from the cross validation results of Table 3, each interpolation method has different degrees of prediction error. In this study, the IP value of OK method is smaller than that of the other three methods for As element, showing some 
advantages. RBF method has the biggest value and obvious disadvantage among the four methods. For $\mathrm{Cu}$ element, the difference of OK method, LPI method and RBF method is small, and the difference of prediction accuracy is small. It is difficult to judge the pros and cons of interpolation method directly according to the results of cross validation. For Mn element, the IP value of OK method is the smallest among the four methods, showing a certain prediction advantage. The IP values of IDW method and RBF method are close, which are higher than those of OK method.

By analyzing the spatial distribution characteristics of element contents in Figure 5, Figure 6 and Figure 7, the OK and LPI methods tend to obtain a smooth surface $(\mathrm{Fu}$ et al.,2014), which can not well reflect the information of local point source pollution, and the smoothing effect is too obvious than the other two methods. As one of the commonly used interpolation methods, OK method is based on the structural characteristics of elements to determine the influence weight of the real value on the predicted value for prediction(Xie et al.,2010). However, the semi-variance function fitting is subjective, and the results of different studies may be different. The OK method also has a strong smoothing effect, which cannot express the information in a small range in detail, which is obvious in the spatial distribution characteristics of $\mathrm{Mn}$ content. Some scholars believe that the OK method will show strong smoothing effect in areas with large variation of element content and poor spatial autocorrelation(Juang \& Lee,2000). This may be because the OK method compresses the change range of data and shows a strong smoothing effect after logarithmic transformation of the element content with poor spatial autocorrelation. The LPI method uses the least square method to fit the spatial distribution trend of element content and tends to obtain a smooth surface( $\mathrm{Fu}$ et al.,2014), which leads to the LPI method cannot reflect the information of local point source pollution. IDW determines weights based on distance, while RBF determines weights based on local smoothing trend(Xie \& Chen \& Lei \& Zheng \& Song \& Li,2010).

IDW method and RBF method belong to deterministic interpolation, that is, the true value at the sample point is equal to the predicted value, and the interpolation results greatly retain the maximum and minimum information of element content(Sun et al.,2017). Gotway et al. (Gotway \& Ferguson \& Hergert \& Peterson,1996) found that the interpolation accuracy of the IDW method was higher than that of the OK method, which was also consistent with the characteristics of the IDW method in this study. Yasrebi et al. analyzed the interpolation accuracy of soil chemical properties, and found that OK was better than IDW. 


\subsection{Analysis of Influencing Factors of Heavy Metal Distribution}

Classification regression is an appropriate method to identify the factors affecting the content of heavy metals in soil. Previous studies have shown that Austrian scholar Claudia Gundacker (Gundacker et al.,2009)conducted bivariate analysis through categorical regression (CATREG) to explain the relationship between $\mathrm{Pb}$ and $\mathrm{Hg}$ exposure and genetic background. Yang(Yang et al.,2020) used classification regression analysis to analyze soil heavy metals for the first time. The results showed that soil parent material, soil type, land use type and industrial activities were the main factors affecting soil heavy metal content in Beijing. In this study, it was found that topography, population density and water source were important sources affecting the soil heavy metals $\mathrm{As}, \mathrm{Cu}$ and $\mathrm{Mn}$ in the central urban area of Chongqing.

The $\mathrm{R}^{2}$ values of the fitting models of the three heavy metals were between 0.449 and 0.734 , and all the fitting models passed the $\mathrm{F}$ test $(\mathrm{P}<0.05)$, with statistical significance. Through the collinearity diagnosis, the variance inflation factor of all variables is $1.16-2.263(\mathrm{VIF}<3$ ), and the tolerance difference is $0.442-0.862$. The tolerance is high enough to ensure the elimination of multiple collinearity problems. For the same heavy metal, the regression coefficients and visibility of different influencing factors are different (Table 4). Beta is used to compare the absolute effect or contribution between the various coefficients. The results of the regression coefficient test by the source of each element sig are significant. On the basis of explicitness check, the relative importance measure is helpful to explain the contribution of CATREG model to regression.

Table 4 Importance of Different Environmental Factors on Distribution of Heavy Metals

\begin{tabular}{cccc}
\hline Influencing factor & $\mathrm{As}$ & $\mathrm{Cu}$ & $\mathrm{Mn}$ \\
\hline Traffic activity & -0.006 & 0.004 & 0.005 \\
Industrial activity & 0.006 & 0.072 & 0.08 \\
Air quality & 0.101 & 0 & 0.11 \\
Soil parent material & -0.065 & 0.207 & 0.201 \\
Slope & 0.177 & 0.002 & 0.206 \\
Population density & 0.069 & 0.539 & 0.163 \\
Soil type & 0.236 & -0.017 & 0.066 \\
NDVI & 0.03 & 0.015 & 0.136 \\
Water environment & 0.453 & 0.178 & 0.034 \\
\hline
\end{tabular}

Compared with other important values, numerical values indicate the importance of these factors. The factors that significantly affect the As content in soil include water environment (0.453), soil type (0.236) and slope (0.177). The factors affecting $\mathrm{Cu}$ content in soil are population density (0.539) and soil parent material (0.207). 
Significant factors affecting Mn content in soil are slope (0.206) and parent material (0.201).

\subsection{Analysis of Spatial Distribution Hotspots of Heavy Metals in Soil}

Hot spot analysis According to the importance of different environmental factors on the distribution of heavy metals in Table 4, the mapping and analysis were carried out according to the maximum influencing factors of each heavy metal. Through the hot spot analysis of heavy metals in soil, the corresponding relationship between the distribution of heavy metals in soil and the spatial distribution of environmental factors was revealed (Figure 8).
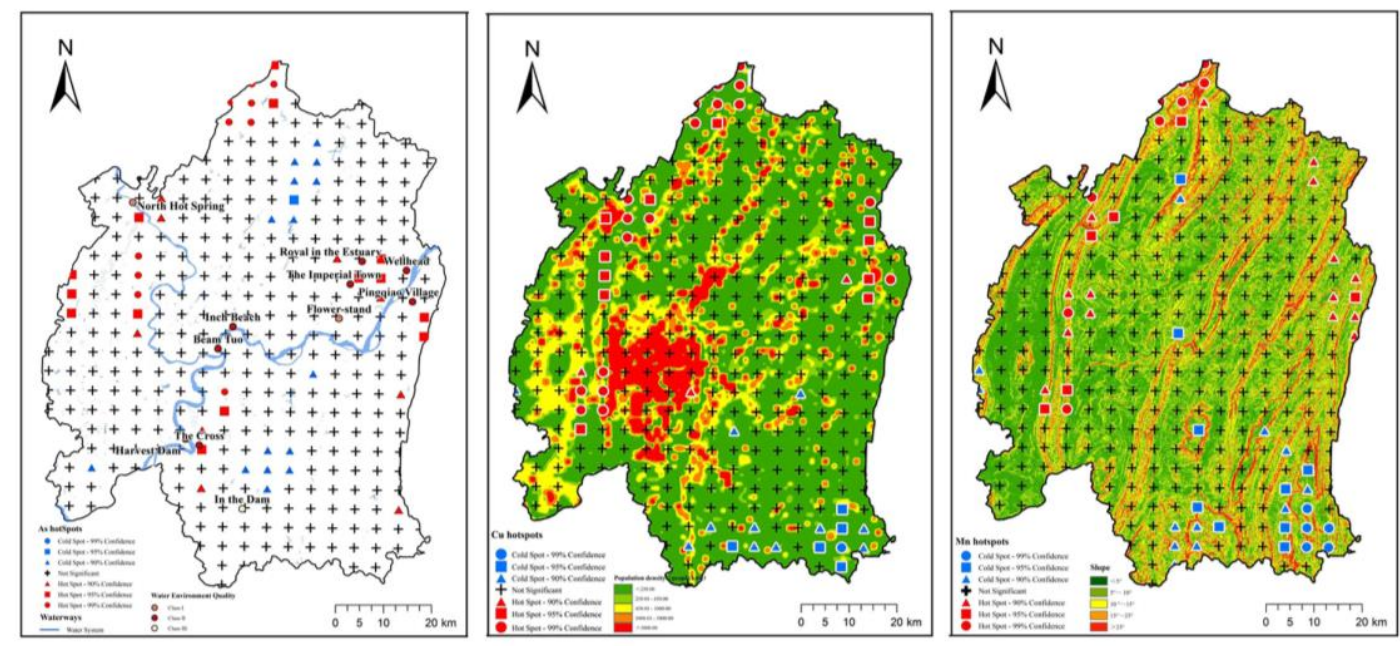

Fig.8 Spatial distribution and influencing factors of heavy metal hotspots in soil : As ( left ), $\mathrm{Cu}$ ( middle ) and $\mathrm{Mn}$ ( right )

The highest hot spot value of soil heavy metal As ( $99 \%$ confidence interval) was mainly distributed in the north and west of the study area. The high hot spot value $(95 \%$ confidence interval) and high hot spot value ( $90 \%$ confidence interval ) are widely distributed, which are located in the northern and western parts of the study area and the eastern part of the concentrated distribution area, adjacent to the secondary water environment area. On the whole, As element has a large coincidence with the secondary water environment area. Water is an important carrier and way of heavy metal movement. The Yangtze River and Jialing River are the core factors of human survival and industrial development. Surface runoff and industrial and agricultural production of drinking water source soil can input large amounts of heavy metals into the environment, resulting in enrichment of heavy metals in water source soil(Davis et al.,2009; Liu et al.,2018). Soil heavy metal As is mainly distributed in the secondary water environment area in the eastern part of the study area in three clusters. Ezekwe(Ezekwe et al.,2012) explored the relationship between heavy metal pollution 
and groundwater in the Ishiagu mining area in southeast Nigeria, and concluded that heavy metals were closely related to the quality of water sources. Some heavy metals in river sediments of water sources mainly come from the leaching effect of surrounding soil. In this study, the eastern region with As enrichment is the downstream region of the river in the study area, which is speculated to be the common result of heavy metals moving along with the river and enrichment in surrounding areas.

The hot spots of $\mathrm{Cu}$ distribution in soil are mainly distributed in the northern, western and eastern regions, and the highest hot spots are mainly located in the surrounding areas of population density $>3000 / \mathrm{km}^{2}$ and $1000-3000 / \mathrm{km}^{2}$. Different population density is closely related to the accumulation of $\mathrm{Cu}$ in soil. Population density is one of the important sources of heavy metals in soil(Manuel TrujilloGonzalez et al.,2016). Based on the analysis of physical and chemical properties, total forms and chemical forms of $\mathrm{Cu}$ in cities and soils with different population densities in the southeast of Spain, the study shows that the behavior of $\mathrm{Cu}$ in dust and soil is affected by physical and chemical properties and total concentrations(Moros et al.,2009). Heavy metals in road dust were investigated in Rafsanjan city, Iran. The results of enrichment factor (EF) evaluation showed that $\mathrm{Cu}$ was the most concerned pollutant. It was found that $\mathrm{Cu}$ was mainly derived from human factors, such as industrial and chemical activities, and heavy traffic(Mirzaei Aminiyan et al.,2018). H. Khadem(Khademi et al.,2020) proposed that there was a strong correlation between $\mathrm{Cu}$ concentration and particle size. It was found that the particle size dependence and element enrichment of metal concentration in street dust were higher than those in urban soil, indicating that anthropogenic pollution had a high contribution to dust.

The hot spots of $\mathrm{Mn}$ in soil are distributed massively in the west, north and east, with the characteristics of slope distribution and the trend of diffusion from the center to the periphery. In the study area, mountains and slopes are cut into a large number of urban groups by rivers. Slope factors are particularly important for the source analysis of heavy metals. The hot spots of Mn in soil have the characteristics of distribution along the slope direction and the trend of diffusion from the center to the periphery. It shows that under the influence of long-term soil erosion, slope runoff and other erosion factors and slope gravity settlement, there is a certain degree of heavy metal accumulation in slope soil(Deng et al.,2020).

\section{Conclusion}

Among the three elements in the study area, the variation coefficient of As element is the highest, which is greatly affected by external factors, and the variation coefficient 
of $\mathrm{Mn}$ is the lowest, which is less affected by external factors. The overall interpolation error of the three element interpolation models is large, and the difference between different methods for the same element prediction is small. The prediction is due to strong human activities and the high spatial variation of urban environment. Based on the cross-validation accuracy evaluation of interpolation results, for As element, the accuracy of OK method is higher than that of the other three methods. For $\mathrm{Cu}$ element, the accuracy differences of OK method, LPI method and RBF method are small; for Mn element, OK method has a certain prediction advantage. Overall, LPI method and OK method showed strong smoothing effect, but IDW method and LPI method can better reflect the extreme value information and local pollution status, which reflects the necessity of using different methods in the study of spatial distribution of soil properties.

CATREG model can not obtain all the influencing factors data, resulting in some deviations, but this method can accurately identify the specific categories of influencing factors. As hot spots are mainly concentrated in the secondary water environment, and the hot spots of soil Mn are distributed along the slope and spread from the center to the periphery. $\mathrm{Cu}$ hotspots are concentrated in areas with population density $>$ $1000 / \mathrm{km}^{2}$. In general, the regions with severe heavy metal pollution are mainly concentrated in the northern, eastern and central parts of the central urban area. The research results provide reference for the prevention and control of soil pollution.

\section{Declarations}

Ethics approval and consent to participate: Not applicable

Consent for publication: Participants have agreed to submit their papers to the journal.

Availability of data and materials: Not applicable

Competing interests: The authors declare no competing interests.

Funding: This paper thanks the support of Chongqing Science and Technology Support Program " Ecological geochemical evaluation of Chongqing metropolitan economic circle " (Approval No.: GITR20050101).

Authors' contributions: Wende Chen was a major contributor in writing the manuscript. Yankun Cai was a major contributor in writing the manuscript and processed the data of organic carbon and total nitrogen. Kun Zhu made the paper's pictures. Jun Wei was a major contributor in writing the paper. Yutian Lu aided in the analysis of data, the layout of the study's design, and made substantial 
revisions to the manuscript. All authors read and approved the final manuscript.

Acknowledgements: We acknowledge the following persons for their role in this paper: Wende Chen, Yankun Cai, Kun Zhu, Jun Wei, Yutian Lu.

\section{[Reference]}

Aguilera, A. , Bautista, F. , Gutiérrez-Ruiz, M. , Ceniceros-Gómez, A. E. , Cejudo, R. , \& Goguitchaichvili, A. Heavy metal pollution of street dust in the largest city of Mexico, sources and health risk assessment. Environmental Monitoring and Assessment, 2021, 193(4).

Almeida, A. , \& Garrod, B. A CATREG model of destination choice for a mature Island destination. Journal of Destination Marketing \& Management, 2018, 8: 32-40.

Chen, C. , Jiang, Y. , \& Yuan, C. Study on Soil Property Spatial Variability Using R Language.

Transactions of the Chinese Society of Agricultural Machinery, 2005, 36(10): 121-124.

Chen, X. , Pan, J. , Wang, W. , \& Li, B. [Landscape Patterns Characteristics of Soil Heavy Metal Pollution in a Town of Southern Jiangsu]. Huan jing ke xue= Huanjing kexue, 2016, 37(6): 2313-2321. Davis, H. T. , Aelion, C. M. , McDermott, S. , \& Lawson, A. B. Identifying natural and anthropogenic sources of metals in urban and rural soils using GIS-based data, PCA, and spatial interpolation. ENVIRONMENTAL POLLUTION, 2009, 157(8-9): 2378-2385.

Dean, E. , Taylor, M. J. , Francis, H. , Lisboa, P. , Appleton, D. , \& Jones, M. A Methodological Framework for Geographic Information Systems Development. SYSTEMS RESEARCH AND BEHAVIORAL SCIENCE, 2017, 34(6): 759-772.

Deng, J. , Li, W. , Xu, W. , He, Z. , \& Tan, X. Correlation and the concentrations of Pb, Cd, Hg and As in vegetables and soils of Chongqing, China. Environmental Geochemistry and Health, 2020.

DeRosa, C. T. , Choudhury, H. , \& Peirano, W. B. An integrated exposure/pharmacokinetic based approach to the assessment of complex exposures. Lead: a case study. Toxicology and industrial health, 1991, 7(4): 231-248.

Feng, R. , Zhao, P. , Zhu, Y., Yang, J. , Wei, X., Yang, L., Liu, H., Rensing, C. , \& Ding, Y. Application of inorganic selenium to reduce accumulation and toxicity of heavy metals (metalloids) in plants: The main mechanisms, concerns, and risks. The Science of the total environment, 2021, 771: 144776.

Fu, C. , Wang, W. , Pan, J. , Zhang, W. , Zhang, W. , \& Liao, Q. A Comparative Study on Different Soil Heavy Metal Interpolation Methods in Lishui District, Nanjing. Chinese Journal of Soil Science, 2014, 45(6): 1325-1333.

Fu, C. , Wang, W. , Pan, J. , Zhang, W. , Zhang, W. , \& Liao, Q. A Comparative Study on Different Soil Heavy Metal Interpolation Methods in Lishui District, Nanjing. Chinese Journal of Soil Science, 2014, 45(6): 1325-1333.

Gotway, C. A. , Ferguson, R. B. , Hergert, G. W. , \& Peterson, T. A. Comparison of kriging and inverse-distance methods for mapping soil parameters. SOIL SCIENCE SOCIETY OF AMERICA JOURNAL, 1996, 60(4): 1237-1247.

Guan, Y. , Zhang, P. , Huang, C. , Wang, D. , Wang, X. , Li, L. , Han, X. , \& Liu, Z. Vertical distribution of Pu in forest soil in Qinghai-Tibet Plateau. JOURNAL OF ENVIRONMENTAL 
RADIOACTIVITY, 2021, 229.

Gundacker, C. , Wittmann, K. J. , Kukuckova, M. , Komarnicki, G. , Hikkel, I. , \& Gencik, M. Genetic background of lead and mercury metabolism in a group of medical students in Austria. Environmental Research, 2009, 109(6): 786-796.

Guo, J. , He, T. , Xie, C. , \& Li, S. Analysis of Heavy Metals Contamination Characteristics of Roadside Soil from Urban Functional Core Area in Chongqing. Journal of Chongqing Normal University. Natural Science Edition, 2016, 33(3): 64-70.

Ivankovic, N. , Kasanin-Grubin, M. , Brceski, I. , \& Vukelic, N. POSSIBLE SOURCES OF HEAVY METALS IN URBAN SOILS: EXAMPLE FROM BELGRADE, SERBIA. JOURNAL OF ENVIRONMENTAL PROTECTION AND ECOLOGY, 2010, 11(2): 455-464.

Juang, K. W. , \& Lee, D. Y. Comparison of three nonparametric kriging methods for delineating heavy-metal contaminated soils. JOURNAL OF ENVIRONMENTAL QUALITY, 2000, 29(1): 197-205.

Kebaili Bargaoui, Z. , \& Chebbi, A. Comparison of two kriging interpolation methods applied to spatiotemporal rainfall. Journal of hydrology (Amsterdam), 2009, 365(1): 56-73.

Khademi, H. , Gabarrón, M. , Abbaspour, A., Martínez-Martínez, S. , Faz, A. , \& Acosta, J. A. Distribution of metal(loid)s in particle size fraction in urban soil and street dust: influence of population density. Environmental Geochemistry and Health, 2020, 42(12): 4341-4354.

Li, J. , \& Wu, Y. Historical changes of soil metal background values in select areas of china. Water, Air, and Soil Pollution, 1991, 57-58(1).

LI, Z. , CHEN, Y. , YANG, X. C. , \& WEI, S. ASSESSMENT OF POTENTIAL ECOLOGICAL HAZARD OF HEAVY METALS IN URBAN SOILS IN CHONGQING CITY. Journal of Southwest Agricultural University, 2006, 28(2): 227-230, 251.

Liu, H., Zhang, Y., Yang, J., Wang, H. , Li, Y., Shi, Y., Li, D. , Holm, P. E. , Ou, Q. , \& Hu, W. Quantitative source apportionment, risk assessment and distribution of heavy metals in agricultural soils from southern Shandong Peninsula of China. Science of The Total Environment, 2021, 767: 144879.

Liu, S. , Jiang, J. , Wang, S. , Guo, Y. , \& Ding, H. Assessment of water-soluble thiourea-formaldehyde (WTF) resin for stabilization/solidification (S/S) of heavy metal contaminated soils. JOURNAL OF HAZARDOUS MATERIALS, 2018, 346: 167-173.

Liu, Z. P. , Shao, M. A. , \& Wang, Y. Q. Large-scale spatial interpolation of soil pH across the Loess Plateau, China. Environmental earth sciences, 2013, 69(8): 2731-2741.

Liu, Z. , Shao, M. , \& Wang, Y. Spatial patterns of soil total nitrogen and soil total phosphorus across the entire Loess Plateau region of China. Geoderma, 2013, 197-198: 67-78.

LIUQing, XIA, J. , \& XIE, W. Application of Semi-variogram and Morans I to Spatial Distribution of Trace Elements in Soil:a Case Study in Shouguang County. Geomatics and Information Science of Wuhan University, 2011, 36(9): 1129-1133.

Ma, H. , Yu, T. , Yang, Z. , Hou, Q. , Zeng, Q. , \& Wang, R. [Spatial Interpolation Methods and Pollution Assessment of Heavy Metals of Soil in Typical Areas]. Huan jing ke xue= Huanjing kexue, 2018, 39(10): 4684-4693.

Manuel Trujillo-Gonzalez, J. , Aurelio Torres-Mora, M. , Keesstra, S. , Brevik, E. C. , \& JimenezBallesta, R. Heavy metal accumulation related to population density in road dust samples taken from urban sites under different land uses. SCIENCE OF THE TOTAL ENVIRONMENT, 2016, 553: 636642 .

McGrath, D. , Zhang, C. S. , \& Carton, O. T. Geostatistical analyses and hazard assessment on soil lead 
in Silvermines area, Ireland. ENVIRONMENTAL POLLUTION, 2004, 127(2): 239-248.

Mirzaei Aminiyan, M. , Baalousha, M. , Mousavi, R. , Mirzaei Aminiyan, F. , Hosseini, H. , \& Heydariyan, A. The ecological risk, source identification, and pollution assessment of heavy metals in road dust: a case study in Rafsanjan, SE Iran. Environmental Science and Pollution Research, 2018, 25(14): 13382-13395.

Moros, J. , Martinez-Sanchez, M. J. , Perez-Sirvent, C. , Garrigues, S. , \& de la Guardia, M. Testing of the Region of Murcia soils by near infrared diffuse reflectance spectroscopy and chemometrics. TALANTA, 2009, 78(2): 388-398.

NIU, W. Inverse Distance Weighting Method Based on Variogram. Journal of Donghua University. Natural Science Edition, 2011, 37(3): 362-367.

Robinson, T. P. , \& Metternicht, G. Testing the performance of spatial interpolation techniques for mapping soil properties. COMPUTERS AND ELECTRONICS IN AGRICULTURE, 2006, 50(2): 97108.

Rodriguez Martin, J. A., Alvaro-Fuentes, J., Gonzalo, J. , Gil, C. , Ramos-Miras, J. J. , Corbi, J. M. G. , \& Boluda, R. Assessment of the soil organic carbon stock in Spain. GEODERMA, 2016, 264: $117-$ 125.

Schöning, I. , Totsche, K. U. , \& Kögel-Knabner, I. Small scale spatial variability of organic carbon stocks in litter and solum of a forested Luvisol. Geoderma, 2006, 136(3): 631-642.

Sun, H. , Guo, Z. , Guo, Y. , Yuan, Y. , Chai, M. , Bi, R. , \& Yang, J. [Prediction of Distribution of Soil Cd Concentrations in Guangdong Province, China]. Huan jing ke xue= Huanjing kexue, 2017, 38(5): 2111-2124.

Voronin, A. D. Modern soil physics as a scientific discipline of Dokuchaev soil science. EURASIAN SOIL SCIENCE, 1996, 29(2): 146-151.

Wang, X. , Sun, Y. , Li, S. , \& Wang, H. Spatial distribution and ecological risk assessment of heavy metals in soil from the Raoyanghe Wetland, China. PLOS ONE, 2019, 14(8).

Wang, Y. , Duan, X. , \& Wang, L. Spatial distribution and source analysis of heavy metals in soils influenced by industrial enterprise distribution: Case study in Jiangsu Province. SCIENCE OF THE TOTAL ENVIRONMENT, 2020, 710.

Wang, Z. , Li, D. , Shang, H. , \& Cheng, J. Theories and methods of geostatistics and its their application in insect ecology. 昆虫知识, 2002, 39(6): 405-411.

WU, L. , FU, W. , YANG, H. , ZHAN, Y. , WANG, J. , \& ZHENG, R. Analysis of Spatial Variability of $\mathrm{Pb}, \mathrm{Cd}$ and Urban Soil Physical and Chemical Properties -A Case Study of Beibei in Chongqing City. Research of Soil and Water Conservation, 2011, 18(5): 171-174.

Xie, H. , Zhang, S. , Hou, S. , \& Zheng, X. Comparison Research on Rainfall Interpolation Methods for Small Sample Areas. Research of Soil and Water Conservation, 2018, 25(3): 117-121.

Xie, Y. , Chen, T. , Lei, M. , Zheng, G. , Song, B. , \& Li, X. Impact of spatial interpolation methods on the estimation of regional soil Cd. Acta Scientiae Circumstantiae, 2010, 30(4): 847-854.

Yang, J., Wang, J., Qiao, P. , Zheng, Y., Yang, J. , Chen, T. , Lei, M. , Wan, X. , \& Zhou, X. Identifying factors that influence soil heavy metals by using categorical regression analysis: A case study in Beijing, China. Frontiers of Environmental Science \& Engineering, 2020, 14(3).

Yang, J., Wang, J., Qiao, P. , Zheng, Y., Yang, J. , Chen, T. , Lei, M. , Wan, X. , \& Zhou, X. Identifying factors that influence soil heavy metals by using categorical regression analysis: A case study in Beijing, China. Frontiers of Environmental Science \& Engineering, 2020, 14(3).

Yang, Y. , Tang, M. , Chen, J. , \& Duan, X. RISK ASSESSMENT OF SOIL HEAVY METAL 
POLLUTION IN A TYPICAL COAL MINE AREA IN CENTRAL CHINA AND ITS EFFECTS ON ENZYME ACTIVITIES. FRESENIUS ENVIRONMENTAL BULLETIN, 2019, 28(5): 4267-4276.

Zhang, R. Theory and application of spatial variation. Beijing: Science press, 2005.

Zhao, K. , Zhang, L. , Dong, J., Wu, J., Ye, Z. , Zhao, W. , Ding, L. , \& Fu, W. Risk assessment, spatial patterns and source apportionment of soil heavy metals in a typical Chinese hickory plantation region of southeastern China. GEODERMA, 2020, 360.

Zhao, Y., Xu, X., Tian, K. , Huang, B. , \& Hai, N. Comparison of sampling schemes for the spatial prediction of soil organic matter in a typical black soil region in China. ENVIRONMENTAL EARTH SCIENCES, 2016, 75(1).

Zheng, H. , Chen, J. , Deng, W. , Tan, M. , \& Zhang, X. SPATIAL ANALYSIS AND POLLUTION ASSESSMENT OF SOIL HEAVY METALS IN THE STEEL INDUSTRY AREAS OF NANJING PERIURBAN ZONE. Acta Pedologica Sinica, 2006, 43(1): 39-45.

Ezekwe, I. C. , Odu, N. N. , Chima, G. N. , \& Opigo, A. Assessing regional groundwater quality and its health implications in the Lokpaukwu, Lekwesi and Ishiagu mining areas of southeastern Nigeria using factor analysis. ENVIRONMENTAL EARTH SCIENCES, 2012, 67(4): 971-986. 